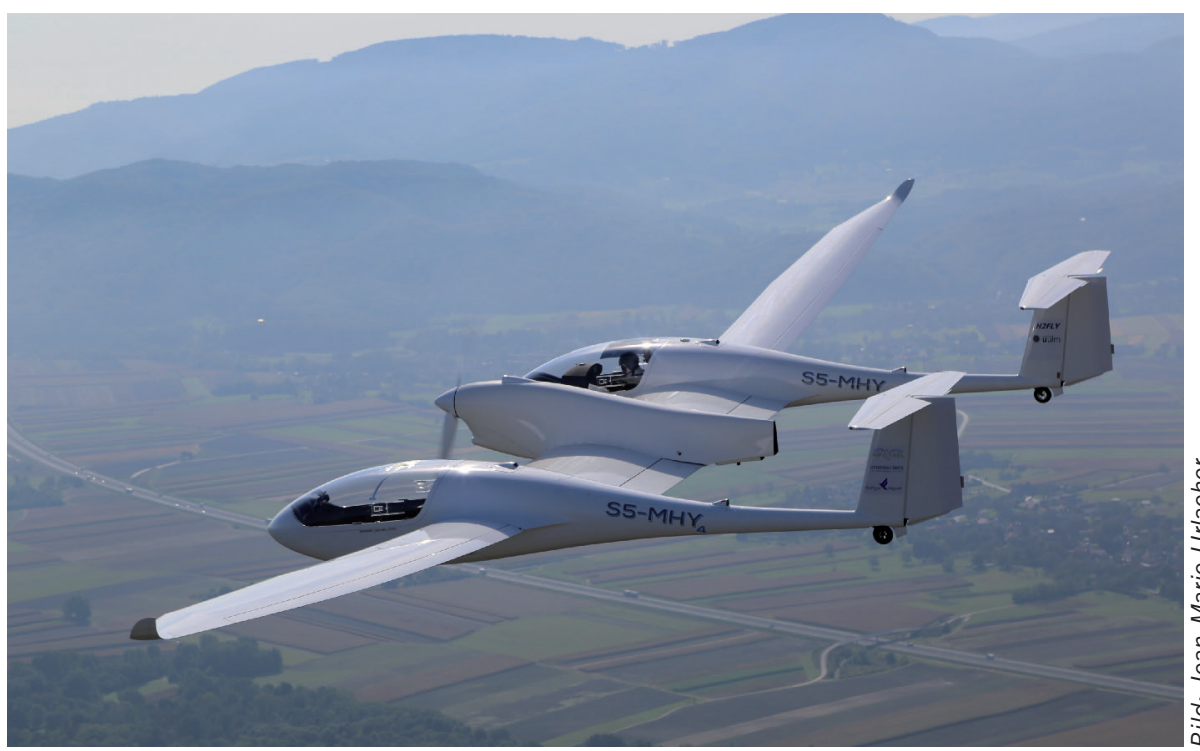

4-sitziges Brennstoffzellenflugzeug HY4.

\section{Wasserstoff und Brennstoffzellen}

Die Wasserstoff- und Brennstoffzellentechnologien haben in den vergangenen Jahren demonstriert, dass sie beim Übergang der Energieversorgung von fossilen hin zu regenerativen Energiequellen eine wichtige Rolle spielen können. Es zeigt sich immer mehr, dass neben der Stromerzeugung aus Wind-, Wasser- und Sonnenenergie andere Herausforderungen wie die Verteilung der Energie auf die verschiedenen Industriesektoren und die Speicherung bei einer Dunkelflaute wichtig werden. Dem Wasserstoff als umweltfreundlichem Energieträger kommt dabei eine besondere Rolle zu, und die Marktreife der verschiedenen Technologien schreitet stetig voran. Durch verschiedene Förderprogramme wird nun die Markteinführung sowie die stetige Weiterentwicklung der benötigten Systeme unterstützt, und so ergaben sich seit dem letztjährigen Fortschrittsbericht [1] eine Vielzahl an technischen Neuerungen und Anwendungen.

D ie Bemühungen der Industrie, die Markeinführung von wasserstoffbasierten Technologien in den kommenden Jahren voranzutreiben, wurden im letzten Jahr noch einmal deutlich intensiviert. Neben den bereits bestehenden nationalen und internationalen Kooperationen haben sich im Januar 2017 in Davos dreizehn führende Unternehmen aus

\section{Autoren}

Dr. Jens Mitzel, wissenschaftlicher Mitarbeiter Polymerorientierte Elektrochemie, Elektrochemische Energietechnik, und Prof. Dr. K. Andreas Friedrich, Abteilungsleiter Elektrochemische Energietechnik, beide Institut für Technische Thermodynamik des Deutschen Zentrums für Luftund Raumfahrt e. V., Stuttgart.
Bericht „How Hydrogen empowers the energy transportation“ [3] zeigt die Visionen dieses neuen Gremiums sowie die benötigten politischen Maßnahmen für deren Umsetzung auf. Die beteiligten Unternehmen betonten zudem ihre Bereitschaft in den kommenden fünf Jahren jährlich mindestens 1,9 Mrd. € in die Markteinführung der Wasserstofftechnologien zu investieren.

Neben der Industrie stellt auch die Politik die benötigten Fördermittel für die Weiterentwicklung und Markteinführung bereit. Seit 2015 erfolgt die Förderung von Forschungs- und Demonstrationsprojekten auf europäischer Ebene über das „Fuel Cells and Hydrogen 2 Joint Untertaking (FCH $2 \mathrm{JU}$ )“ im Rahmen des Horizon-2020-Programms [4]. Hierdurch sollen bis 2020 unter anderem die Anzahl brennstoffzellenbetriebener Fahrzeuge erhöht und die dafür benötigte Tankinfrastruktur und Wasserstofferzeugung erweitert sowie die Verbreitung brennstoffzellenbasierter Kraft-Wärme-Kopplungs (KWK)-Anlagen gesteigert werden.

In Deutschland endete 2016 die erste Phase des 2008 begonnenen, nationalen Innovationsprogramms Wasserstoff und Brennstoffzelle (NIP), mit dem 1,4 Mrd. € in den Aufbau und die Markerprobung der Wasserstofftechnologie investiert wurden. 500 Mio. € stellte das Bundesministerium für Verkehr und digitale Infrastruktur (BMVI) und 200 Mio. $€$ das Bundesministerium für Wirtschaft und Energie (BMWi) zur Verfügung. Die Industrie beteiligte sich mit weiteren 700 Mio. $€$. Durch die Förderung von mehr als 650 Einzelprojekten erreichte das NIP in seiner 8-jährigen Laufzeit eine signifikante Weiterentwicklung der Wasserstofftechnologie und trug zum Aufbau der Wasserstoffbranche, mit derzeit über 500 Unternehmen und Forschungseinrichtungen, bei. Im September 2016 wurde nun das Regierungsprogramm „Wasserstoff- und Brennstoffzellentechnologie 2016 bis 2026" verabschiedet, und so wird das NIP bis 2026 fortgeführt. Dazu werden bis Ende 2019 zunächst 250 Mio. € vom BMVI bereitgestellt [5].

Die technischen Neuerungen und die fortschreitende Markteinführung der Wasserstoff- und Brennstoffzellentechnologien im vergangenen Jahr umfassen verschiedenste Anwendungen von Brennstoffzellensystemen für die Energieversorgung von Wohnhäusern, in der Industrie und im Transportsektor sowie Anlagen zur Wasserstofferzeugung und -bereitstellung für die verschiedenen Sektoren. 


\section{Stationäre \\ Brennstoffzellensysteme}

Wie bereits in der letztjährigen Jahresübersicht zum Thema Wasserstoff und Brennstoffzellen [1] aufgezeigt, haben Mikro-KWK-Anlagen in Japan bereits die Hürde der Markteinführung überwunden, und jährlich werden mehrere Zehntausend solcher Anlagen neu installiert. Im Juni 2016 versorgten schon mehr als 170000 Mikro-KWK-Anlagen mit Brennstoffzellen japanische Haushalte mit Strom und Wärme [6]. Hingegen war die Einführung solcher Anlagen in Europa auf wenige europäische und nationale Demonstrationsprojekte mit einigen Hundert Geräten beschränkt. Im Rahmen von Horizon 2020 hat nun am 1. Juni 2016 das größer angelegte Projekt Pace (Pathway to a Competitive European FC mCHP market) begonnen, in dem bis 2021 insgesamt 2650 neue Anlagen bei Kunden installiert und deren Betrieb auf weitere Optimierungsmöglichkeiten analysiert werden sollen [7]. So sollen die Anlagenkosten um weitere $30 \%$ reduziert und die Lebensdauer der verbauten Brennstoffzellen auf über zehn Jahre erhöht werden. Hierzu werden die beteiligten Firmen Bosch, Solidpower, Vaillant und Viessmann die Anlagenproduktion weiterentwickeln, um ihre jährliche Produktionskapazität bis 2018 auf 1000 Anlagen pro Jahr zu erweitern. Innerhalb des Projektes sollen zusammen mit den Projektpartnern Element Energy, EWE, Technische Universität Dänemark (DTU) und BDR Thermea Group je 500 Anlagen direkt bei Kunden installiert und in Betrieb genommen werden.

Um den nächsten Schritt in den kommerziellen Markt in Deutschland zu unterstützen, wurde vom BMWi 2016 das Technologieeinführungsprogramm (TEP) für stationäre Brennstoffzellen zur Hausenergieversorgung initiiert. Zwar existieren bereits mehrere Förderprogramme für KWK-Anlagen, die auch die Förderung der Brennstoffzellen-KWK ermöglichen, das TEP schließt jedoch die Lücke eines speziell auf die Endkunden zugeschnittenen Förderprogramms, das direkt auf die Erhöhung der Verkaufs- und Installationszahlen von Brennstoffzellen-KWKAnlagen abzielt. Das im Dezember 2016 gestartete TEP soll die Installation von bis zu 75000 Anlagen bis zum Jahr 2023 unterstützen und zusätzliche Kaufanreize liefern. Die Förderung erfolgt als Zuschuss beim Kauf einer neuen BrennstoffzellenKWK-Anlage im Leistungsbereich zwischen $250 \mathrm{~W}$ und $5 \mathrm{~kW}$ mit einem Grund-

\begin{tabular}{|c|c|c|}
\hline $\begin{array}{c}\text { Elektrische Leistung } \\
{[\mathbf{k W}]}\end{array}$ & $\begin{array}{c}\text { Basisförderung } \\
{[€ / \mathbf{k W}]}\end{array}$ & $\begin{array}{c}\text { Elektrischer Wirkungsgrad für } \\
\mathbf{6 0} \% \text { Bonusförderung }\end{array}$ \\
\hline $\mathbf{0}$ bis 1 & 1900 & $>31 \%$ \\
\hline $\mathbf{1}$ bis 4 & 300 & $>31 \%$ \\
\hline $\mathbf{4}$ bis 10 & 100 & $>33 \%$ \\
\hline 10 bis 20 & 10 & $>35 \%$ \\
\hline
\end{tabular}

betrag von $5700 €$ und einer zusätzlichen, leistungsabhängigen Förderung von $450 €$ pro $100 \mathrm{~W}$ installierter, elektrischer Leistung [8], wobei maximal $40 \%$ der förderfähigen Kosten bezuschusst werden. Die Förderung im TEP erfolgt durch die KfW-Bank unter der Bezeichnung „Energieeffizient Bauen und Sanieren - Zuschuss Brennstoffzelle" mit der Programmnummer 433 [9] und ist Teil des Anreizprogrammes Energieeffizienz (APEE). Beispielhaft betragen die möglichen Fördersummen bei einer Brennstoffzellen-KWK-Anlage mit einer elektrischen Leistung von $1 \mathrm{~kW} 10200 €$ und kann bei einer 5 -kW-Anlage bis $\mathrm{zu}$ $28200 €$ erreichen. Weiterhin besteht auch die Möglichkeit der Bafa-Stromförderung (Bundesamt für Wirtschaft und Ausfuhrkontrolle), die allerdings nicht mit der Förderung aus dem TEP kombiniert werden kann [10]. Die entsprechende Basisförderung richtet sich hier ebenfalls nach der elektrischen Leistung der KWK-Anlage und ist entsprechend Tabelle 1 gestaffelt, wobei sich die Förderung kumulativ aus den einzelnen Stufen zusammensetzt. Diese Basisförderung erhöht sich bei Anlagen, die einen Brennwertwärmeaustauscher besitzen und hydraulisch abgeglichen sind, um eine Bonusförderung für „Wärmeeffizienz" von $25 \%$ und bei KWK-Anlagen mit besonders hohem elektrischen Wirkungsgrad, wie die brennstoffzellenbasierten Anlagen, um einen Bonus „Stromeffizienz“ von $60 \%$ der Basisförderung. Bezogen auf das bereits aufgeführte Beispiel ergibt sich somit für eine 1-kW-Anlage eine Förderung von $3515 €$ $(1900 €+85 \%)$ und für eine 5-kW-Anlage von $5365 €(2900 €$ +85\%). Die Förderung beim Kauf von MikroKWK-Anlagen mit Brennstoffzellentechnik hat sich somit durch das TEP deutlich verbessert, und die Bafa-Stromförderung ist nur noch für Anla-

Bild 1 Vergleich jährlicher Heizkosten für ein $150-m^{2}$-Haus.
Tabelle 1 Staffelung der Bafa-Stromförderung.

gen über $5 \mathrm{~kW}$ attraktiv.

Zusätzlich zu den beiden Fördermöglichkeiten bei der Anschaffung einer solchen Mikro-KWK-Anlage erhalten die Betreiber nach dem in 2016 erneuerten KWK-Gesetz einen Zuschlag, der sich nach der erzeugten Strommenge richtet. Bei Anlagen mit einer Leistung von maximal $50 \mathrm{~kW}$ beträgt dieser $4 \mathrm{Ct} / \mathrm{kWh}$ bei Eigenverbrauch und $8 \mathrm{Ct} / \mathrm{kWh}$ bei Einspeisung ins Stromnetz [11]. Unter Berücksichtigung dieser Vergütung für die Eigenstromproduktion hat die ASUE (Arbeitsgemeinschaft für sparsamen und umweltfreundlichen Energieverbrauch e. V.) die Verbrauchs- und Betriebskosten verschiedener Heizsysteme am Beispiel eines 150- $\mathrm{m}^{2}$-Hauses berechnet und gegenübergestellt [12]. Daraus ergibt sich, dass bei der Nutzung von Brennstoffzellensystemen die jährlichen Heizkosten am geringsten sind (Bild 1). Zusammen mit den durch das TEP verringerten Anschaffungskosten stellt eine brennstoffzellenbasierte Mikro-KWK-Anlage für den Kunden somit mittlerweile eine sehr attraktive Lösung für die Versorgung von Eigenheimen mit Strom und Wärme dar.

Es befinden sich bereits mehrere Anlagen auf dem Markt, die zur Hausenergieversorgung genutzt werden können und von den neuen Förderrichtlinien profitieren [13]. Die zur Verfügung stehenden Mikro-KWK-Anlagen sind in Tabelle 2 in alphabetischer Reihenfolge der Hersteller zusammengefasst. Die eingesetzten Brennstoffzellensysteme basieren dabei

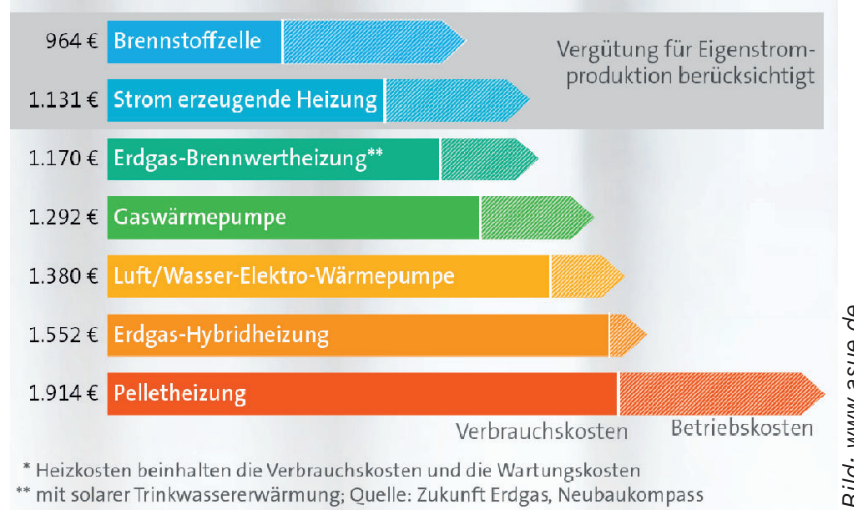




\begin{tabular}{|c|c|c|c|c|c|c|}
\hline Hersteller & KWK-Anlage & $\begin{array}{c}\text { Elektrische } \\
\text { Leistung } \\
\text { [kW] }\end{array}$ & $\begin{array}{c}\text { Thermische } \\
\text { Leistung } \\
\text { [kW] }\end{array}$ & $\begin{array}{c}\text { Elektrischer } \\
\text { Wirkungsgrad } \\
{[\%]}\end{array}$ & $\begin{array}{c}\text { Gesamt- } \\
\text { Wirkungsgrad } \\
{[\%]}\end{array}$ & Technologie \\
\hline Buderus & $\begin{array}{l}\text { Logapower } \\
\text { FC10 }\end{array}$ & 0,7 & 0,62 & 45 & 85 & SOFC \\
\hline Elcore & Elcore 2400 & 0,3 & 0,7 & 32 & 104 & HT-PEMFC \\
\hline Hexis & Galileo 1000 N & 1,0 & 1,8 & 35 & 95 & SOFC \\
\hline Junkers & CeraPower FC & 0,7 & 0,62 & 45 & 85 & SOFC \\
\hline RBZ & Inhouse $5000+$ & 5,0 & 7,5 & 34 & 92 & NT-PEMFC \\
\hline SenerTec & Dachs InnoGen & 0,7 & 0,96 & 37 & 93 & NT-PEMFC \\
\hline \multirow[t]{2}{*}{ SOLIDpower } & BlueGEN & 1,5 & 0,61 & 60 & 85 & SOFC \\
\hline & Engen-2500 & 2,5 & 2,0 & 50 & 90 & SOFC \\
\hline Vaillanta) & XellPOWER & 0,7 & 1,3 & 33 & 90 & SOFC \\
\hline Viessmann & Vitovalor 300-P & 0,75 & 1,0 & 37 & 90 & NT-PEMFC \\
\hline
\end{tabular}

Tabelle 2 Mikro-KWK-

Anlagen auf Brennstoffzellenbasis.

den in Deutschland mittlerweile auch immer mehr Verwendung bei der Notstromversorgung des Digitalfunks für Behörden und Organisationen mit Sicherheitsaufgaben (BOS). So erfolgt seit Ende Mai 2016 auch die Absicherung von 44 BOS-Basisstationen in Bayern über PEMFC-Systeme im Leistungsbereich zwischen 4 und $8 \mathrm{~kW}$, die den Funkbetrieb bei

auf der Festoxidbrennstoffzelle (SOFC, Solid Oxide Fuel Cell) sowie der Niedertemperatur (NT-PEMFC)- und Hochtemperatur-Polymer-Elektrolyt-Membran-Brennstoffzelle (HT-PEMFC). Um den erhöhten Wärmebedarf im Winter abzudecken, werden die dargestellten Anlagen mit Gas-Brennwertkesseln kombiniert, die je nach Hersteller direkt in die Geräte integriert sind oder extern bereitgestellt werden.

Größere, brennstoffzellenbetriebene Kraftwerke, wie sie zur Versorgung von Industrieanlagen mit Strom und Wärme zum Einsatz kommen, beruhen aufgrund der höheren Effizienz und guten Langlebigkeit bei seltenen Lastwechseln auf Hochtemperaturbrennstoffzellen. Die beiden amerikanischen Marktführer FuelCell Energy und BloomEnergy nutzen dazu mit Schmelzcarbonat-Brennstoffzellen (MCFC, Molten Carbonate Fuel Cells) und SOFC unterschiedliche Technologien, die jedoch beide Erdgas als Brennstoff nutzen. Zwar ist die Technologie damit nicht emissionsfrei, kann die $\mathrm{CO}_{2}$-Emissionen aber erheblich senken, da die elektrische Effizienz mit bis zu $47 \%$ deutlich über der von konventionellen Kraftwerken mit etwa $27 \%$ liegt. Alleine in den USA stieg bis zum November 2016 die Leistung der brennstoffbetriebenen Kraftwerke auf über $235 \mathrm{MW}$ an [14]. So wurde beispielsweise im November 2016 eine 5,6-MW-Anlage auf dem Gelände des Pfizer Forschungs- und Entwicklungszentrums in Connecticut in Betrieb genommen [15]. Die Anlage beruht auf der MCFC-Technologie und wurde von FuelCell Energy innerhalb von gerade einmal zehn Monaten aufgebaut. Sie deckt etwa die Hälfte des Energiebedarfs von Pfizer vor Ort. Im Oktober 2016 wurde zudem bekannt, dass FuelCell Energy mit einer 2,3-MW-MCFC-Pilotanlage in Alabama eine interessante Möglichkeit dieser Technologie zur $\mathrm{CO}_{2}$-Abscheidung und späte- ren Speicherung in unterirdischen Lagerstätten (CCS, Carbon Dioxide Capture and Storage) untersucht [16]. Die Anlage ist direkt an ein konventionelles Kraftwerk von ExxonMobil gekoppelt und soll die $\mathrm{CO}_{2}$-Emissionen dieses Kraftwerkes senken, indem Teile des $\mathrm{CO}_{2}$ durch die MCFC aufkonzentriert und so der Speicherung zugänglich gemacht werden. Im Unterschied $\mathrm{zu}$ anderen CCS-Techniken wird dabei keine Energie benötigt, um das $\mathrm{CO}_{2}$ abzutrennen, sondern in der MCFC wird noch Energie erzeugt und so die Energiebilanz des Prozesses deutlich verbessert.

Des Weiteren hat Mitsubishi Hitachi Power Systems den Prototypen Model 15, der seit 2015 an der Kyushu University in Japan erprobt wurde [1], zu einem serienreifen Produkt weiterentwickelt. Dieses Hybridkraftwerk mit einer Leistung von $250 \mathrm{~kW}$ beinhaltet eine SOFC, die mit Wasserstoff und Kohlenmonoxid aus einem Erdgasreformer betrieben wird. Der Restbrennstoff im Abgas des SOFC-Stacks wird in einer Mikrogasturbine (MGT) ebenfalls in elektrische Energie überführen. Die dabei in der MGT verdichtete Luft wird wiederum dem SOFC-Stack zugeführt, um dessen Effizienz zu erhöhen. Durch diese Hybridisierung der beiden Technologien erreicht das Hybridkraftwerk eine elektrische Gesamteffizienz von bis zu $55 \%$. Die neue Anlage wurde in der Senju Techno Station von der Tokyo Gas Co. installiert und hat ihren Testbetrieb im September 2016 aufgenommen [17]. Drei weitere Testanlagen sollen bei der Toyota Motor Corporation, der NGK Spark Plug Co. und der Taisei Corporation aufgebaut werden, um Effizienz, Bedienbarkeit, Betriebskosten und Langlebigkeit in industrieller Umgebung weiter zu verbessern. Die kommerzielle Markteinführung des Modells ist noch im Laufe des Jahres 2017 geplant.

Stationäre Brennstoffzellensysteme fin-
Stromausfällen für mindestens 72 Stunden gewährleisten können [18]. Die Anlagen konzentrieren sich dabei auf Standorte mit erschwerter Zugänglichkeit und unter klimatisch anspruchsvollen Bedingungen in voralpinen und alpinen Regionen und sollen den Reifegrad der Brennstoffzellentechnik unter diesen Rahmenbedingungen demonstrieren. Damit sind deutschlandweit etwa 220 BOS-Stationen mit Notstromaggregaten auf Brennstoffzellenbasis ausgerüstet.

\section{Automobile}

\section{Brennstoffzellenanwendungen}

Auf dem Automobilmarkt hat zusätzlich zu den bereits in den Vorjahren etablierten, brennstoffzellenbetriebenen Fahrzeugen (FCEV, Fuel Cell Electric Vehicles) Hyundai ix35 und Toyota Mirai mit Honda der dritte asiatische Hersteller mit einer Kleinserie dieser Fahrzeuge begonnen, und noch in 2017 soll mit Daimler der erste europäische Hersteller bei der seriennahen Fertigung von FCEV folgen. Neben der Markteinführung dieser Fahrzeuge wurden 2016 weitere Prototypen vorgestellt, die mit Brennstoffzellensystemen zur Reichweitenerhöhung von batterieelektrischen Fahrzeugen ausgerüstet sind. Außerdem wurde ein Car-SharingDienst sowie eine Taxiflotte in Europa initiiert, die die FCEV der Öffentlichkeit zugänglich machen und wichtige Daten für die Weiterentwicklung der FCEV liefern.

Nach der Präsentation des Honda Clarity Fuel Cell (Bild 2) im Oktober 2015 auf der Tokyo Motor Show und im März 2016 auf dem Genfer Autosalon wurde das erste Fahrzeug Mitte März 2016 dem japanischen Ministerium für Wirtschaft, Handel und Industrie (METI) übergeben und der Verkauf des Clarity Fuel Cell in Japan gestartet [19]. In Europa wurden die ersten Fahrzeuge im Rahmen des HyFiveProjektes in London und in Kopenhagen ausgeliefert [20]. In den USA ist der Wa- 
gen seit Dezember 2016 zunächst als Leasingfahrzeuge in Kalifornien erhältlich. Der Clarity Fuel Cell ist eine 4-türige Limousine mit einem 130 PS starken Elektromotor und einer Reichweite von $589 \mathrm{~km}$ bei einer Wasserstoffspeicherkapazität von $5 \mathrm{~kg}$. Laut der United States Environmental Protection Agency (EPA) besitzt der Clarity Fuel Cell damit die größte Reichweite aller in Amerika erhältlichen, emissionsfreien Fahrzeuge [21]. Das kompakte 103-kW-Brennstoffzellensystem befindet sich vollständig im Motorraum, wodurch im Innenraum Platz für fünf Passiere realisiert werden konnte. In 2016 wurden zunächst 200 Fahrzeuge vorwiegend für den japanischen Markt gefertigt [22].

Die Markteinführung des ersten deutschen und auch europäischen FCEV in Kleinserienfertigung durch die Daimler AG nimmt derzeit immer konkretere Formen an. Bei dem GLC F-Cell (Bild 2) handelt es sich um einen SUV, der im Herbst 2017 auf dem Markt kommen soll [23]. Um dem schrittweisen Aufbau der Wasserstofftankstelleninfrastruktur gerecht zu werden, handelt es sich um das erste Brennstoffzellen-Plug-In-HybridFahrzeug auf dem Markt. Neben der Brennstoffzelle besitzt der GLC deutlich größere Lithium-Ionen-Batterien als dies in anderen FCEV üblich ist. Mit den etwa $9 \mathrm{kWh}$ starken Batterien können bis zu $50 \mathrm{~km}$ rein batterieelektrisch gefahren und an jeder Haushaltssteckdose oder Elektroladestation aufgeladen werden. Die etwa $4 \mathrm{~kg}$ Wasserstoff aus den $700 \mathrm{bar}$ Drucktanks des GLC erhöhen die Reichweite dann auf etwa $500 \mathrm{~km}$ [24]. Das eingesetzte PEMFC-System ist etwa 30\% kompakter als bisherige Systeme [25], was (wie beim Honda Clarity Fuel Cell) die vollständige Integration des Systems im klassischen Motorraum erlaubt, eine wichtige Voraussetzung für die fortschreitende Serienreife der Brennstoffzellentechnik im Pkw-Bereich und die Fließbandfertigung von FCEV. Das gesamte Brennstoffzellensystem des GLC verwendet lediglich noch $20 \mathrm{~g}$ des teuersten Rohstoffes des Brennstoffzellenherstellung, des Edelmetallkatalysators Platin. Die damit verbundene Kostenreduktion stellt ein weiteres wichtiges Kriterium für die Wettbewerbsfähigkeit der Fahrzeuge dar, und der Preis des GLC F-Cell soll bei etwa $60000 €$ liegen [26]. Damit wäre der GLC in Deutschland günstiger als bisher verfügbare Brennstoffzellenfahrzeuge wie der Hyundai ix35 Fuel Cell mit einem aktuellen Preis von $64450 €$ und der Toyota

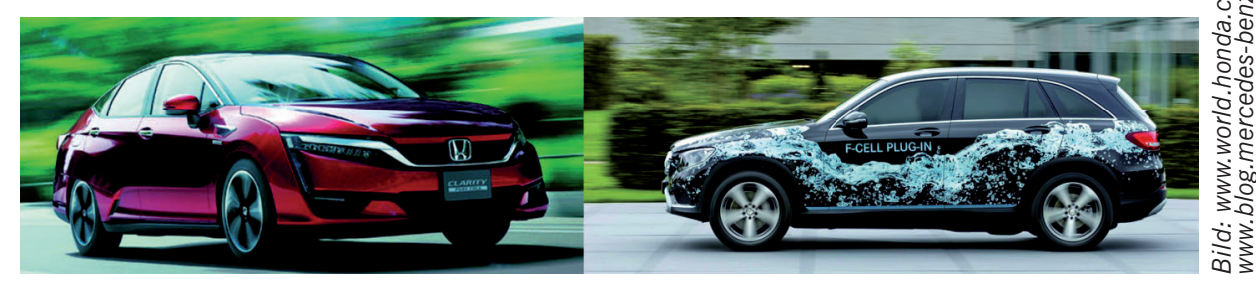

Bild 2 Honda Clarity Fuel Cell (links) und Daimler GLC F-Cell.

Mirai mit $78500 €[1]$ und würde als einziges FCEV in Deutschland von der Förderung beim Erwerb eines Elektrofahrzeugs profitieren, bei der der Listenpreis der Fahrzeuge $60000 €$ nicht überschreiten darf. Die Endfertigung des GLC F-Cell erfolgt im Daimler-Werk in Bremen, während die einzelnen Systemkomponenten an verschiedenen Stellen in Deutschland und Kanada entwickelt und gefertigt werden [27]. Der PEMFC-Stack wurde von Daimler zusammen mit Ford und AFCC (Automotive Fuel Cell Cooperation) in Vancouver entwickelt und wird für die Kleinserie von MBFC (Mercedes-Benz Fuel Cell) in Burnaby gefertigt. Das Brennstoffzellensystem wurde von der Daimler-Tochter NuCellSys in Kirchheim entwickelt und wird im Daimlerwerk in Untertürkheim gefertigt. Die Entwicklung des Wasserstoffspeichersystems wurde ebenfalls von NuCellSys realisiert, und die Fertigung der Tanks erfolgt im Daimlerwerk in Mannheim. Die Lithium-Ionen-Batterien liefert die Daimler-Tochter Deutsche Accumotive in Kamenz.

Neben der Nutzung von Brennstoffzellensystemen mit etwa $100 \mathrm{~kW}$ elektrischer Leistung als Hauptantrieb in Fahrzeugen werden Brennstoffzellen auch zunehmend zur Erhöhung der Reichweite von batterieelektrischen Fahrzeugen in so genannten Range-Extender-Systemen eingesetzt. Hier kommen Systeme mit einer elektrischen Leistung in einer Größenordnung von $5 \mathrm{~kW}$ zum Einsatz, die die Batterien eines kommerziell etablierten Elektrofahrzeugs im Betrieb wie im Stillstand aufladen und so deren Reichweite mehr als verdoppeln können. Ein Beispiel eines solchen Fahrzeugs ist der Kangoo ZE-H2 von der französischen Firma SymbioFCell (Bild 3). Durch die Integration des $5 \mathrm{~kW}$ starken PEMFC-Range-

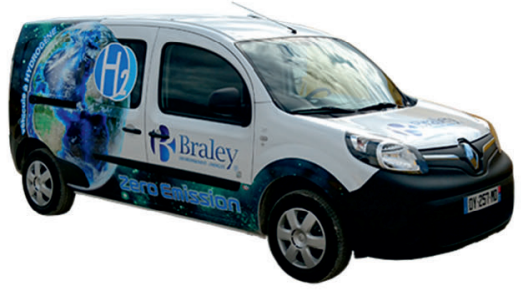

Extenders ALP5 in einen Renault Kangoo ZE mit einer Batteriekapazität von $22 \mathrm{kWh}$ konnte die Reichweite dieses elektrisch betriebenen Lieferfahrzeugs von 100 auf über $300 \mathrm{~km}$ erhöht werden. Je nach verwendetem Wasserstoffspeicher stehen dem Kangoo so zusätzliche $26 \mathrm{kWh}$ aus $1,78 \mathrm{~kg}$ Wasserstoff (350 bar Tank) beziehungsweise $30 \mathrm{kWh}$ aus 2,03 kg Wasserstoff (700 bar Tank) mit einer Tankfüllung zur Verfügung [28]. Mit diesem Fahrzeug wurde im September 2016 ein neuer Reichweitenweltrekord für leichte Elektronutzfahrzeuge im realen Lieferverkehr in Städten erzielt, bei dem innerhalb von etwa zehn Stunden eine Lieferstrecke von $367 \mathrm{~km}$ zurückgelegt wurde [29].

Während alle bisher aufgeführten Fahrzeuge aufgrund des schnellen Ansprechverhaltens auf PEMFC-Systemen mit Wasserstoffdrucktanks beruhen, verfolgt Nissan einen anderen Ansatz zur nachhaltigen Energieversorgung des Transportsektors. Im Juni 2016 wurde die Entwicklung eines SOFC-Systems angekündigt, das mit Bioethanol betrieben werden kann und ebenfalls das Konzept eines Brennstoffzellen-Range-Extender gekoppelt mit einer größeren Batterie verwendet [30]. Das System beinhaltet einen Reformer, der das Ethanol in Wasserstoff umsetzt, der dann in einer SOFC mit der Umgebungsluft umgesetzt wird. Aufgrund des höheren elektrischen Wirkungsgrades der SOFC und der hohen Speicherdichte des flüssigen Brennstoffes verspricht sich Nissan eine weitere Steigerung der Reichweite eines so betriebenen FCEV. Die Nutzung von Bioethanol als Treibstoff hat außerdem den Vorteil, dass die bereits gut ausgebaute Tankstelleninfrastruktur bei-

Bild 3 SymbioFCell Kangoo ZE-H2 (links) und Nissan-e-Bio-Fuel-Cell-Prototyp.

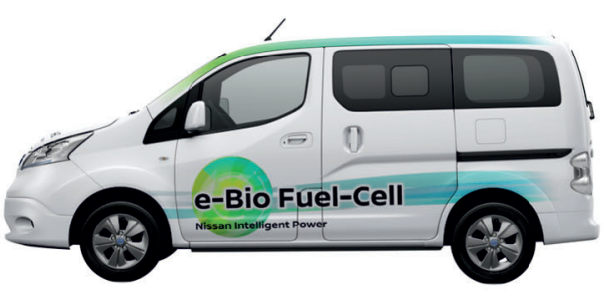




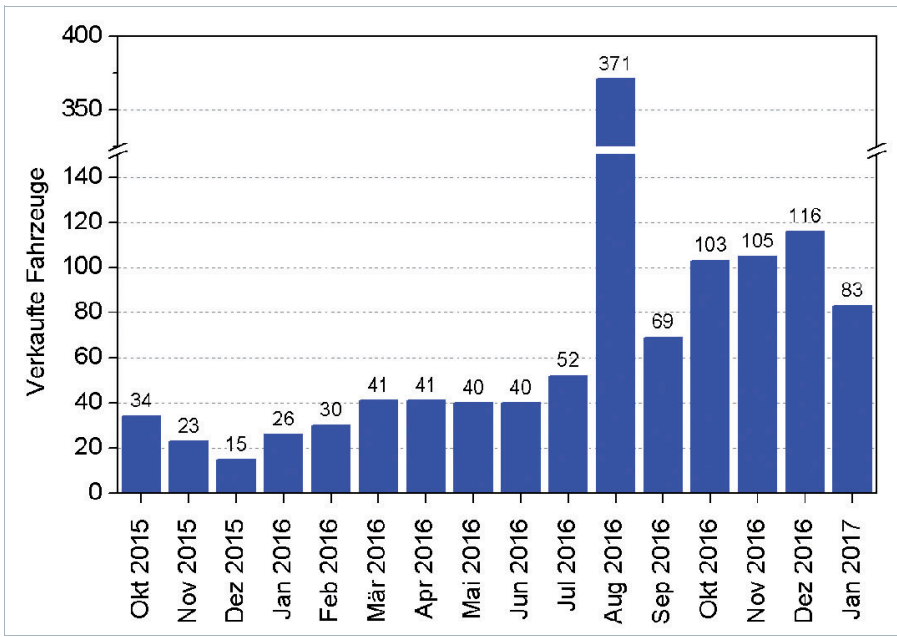

spielsweise in Nord- und Südamerika sowie in Asien direkt genutzt werden kann. Allerdings besitzen diese Fahrzeuge nicht mehr den Vorteil, lokal kein $\mathrm{CO}_{2}$ zu emittieren, arbeitet aber dennoch $\mathrm{CO}_{2}$-arm. Der erste e-Bio-Fuel-Cell-Prototyp (Bild 3) befindet sich derzeit in der Erprobung in Brasilien, einem Land mit bekanntermaßen hohem Bioethanolanteil bei Fahrzeugantrieben [31]. Der Prototyp basiert auf dem Nissan e-NV200, einem elektrisch betriebenen Kleintransporter, und ist mit Lithium-Ionen-Batterien mit einer Kapazität von $24 \mathrm{kWh}$ und einem SOFCRange-Extender mit einer elektrischen Leistung von $5 \mathrm{~kW}$ ausgerüstet. Mit einer Tankkapazität von 301 Bioethanol sollen so Reichweiten von deutlich über $600 \mathrm{~km}$ erreicht werden.

Das gleiche Konzept eines jedoch methanol-betriebenen Range Extenders auf Brennstoffzellenbasis verfolgt auch SerEnergie aus Dänemark, allerdings werden hier HT-PEMFC-Systeme genutzt, um die Reichweite von dem batteriebetriebenen Fiat e500 von 100 auf bis zu 800 km zu verbessern [32]. Der $5 \mathrm{~kW}$ starke Range Extender H3 5000 ist dabei als Modul konzipiert, das prinzipiell in jedes Elektrofahrzeug integriert werden kann und mit einer 60-prozentigen Methanollösung betrieben wird. Auch hier wird zwar lokal $\mathrm{CO}_{2}$ emittiert, aufgrund der geringen Betriebstemperatur von etwa $200^{\circ} \mathrm{C}$ entstehen jedoch keine $\mathrm{NO}_{\mathrm{X}^{-}}$oder $\mathrm{SO}_{\mathrm{X}^{-}}$ Emissionen, und wie alle Brennstoffzellen arbeitet das System geräuscharm und ohne Entwicklung von Feinstaub. Seit Dezember 2016 wurde das Konzept vom dänischen Lieferservice für Nahrungsmittel Just Eat zunächst erprobt und ist mittlerweile fester Bestandteil der Lieferflotte [33].

Auch wenn die Anzahl der FCEV weltweit steigt, ist es schwierig, die bisherigen
Bild 4 Verkaufszahlen des Toyota Mirai in den USA.

Produktionszahlen der einzelnen Fahrzeuge und die Verteilung der Fahrzeuge auf dem Markt zuverlässig zu bestimmen. Bis zum Februar 2017 hat Toyota insgesamt 2840 Mirai im Wesentlichen in Japan und den USA auf den Markt gebracht [34]. Nur für die USA liegen dabei Daten vor, wie sich die Verkaufszahlen seit der Markteinführung im Oktober 2015 entwickelt haben [35]. Wie Bild 4 zeigt, steigen die Verkaufszahlen dort stetig an, und insgesamt wurden bis zum Januar 2017 etwa 1200 Mirai an Kunden übergeben. Der bisher verkaufsstärkste Monat war der August 2016, in dem Toyota-Mitarbeitern vergünstigte Leasingkonditionen angeboten wurden [36]. Allerdings musste Toyota im Februar 2017 auch die erste Rückrufaktion für den Mirai hinnehmen. Die gesamte Mirai-Flotte musste aufgrund eines Problems mit der Steuerungselektronik $\mathrm{zu}$ einem etwa halbstündigen Serviceupdate in die Werkstätten, da es unter bestimmten Bedingungen dazu kommen konnte, dass die Ausgangsspannung des Spannungswandlers die maximal zulässige Systemspannung überschritt [34].

Die höhere Reichweite und schnelle Betankung von FCEV im Vergleich zu anderen elektrisch betriebenen Fahrzeugen wird zunehmend auch beim Personentransport mit alternativen Mobilitätskonzepten, wie dem Car Sharing oder dem Taxibetrieb, genutzt. Diese Konzepte ermöglichen es, die Anzahl von FCEV auf der Straße zu erhöhen, die Auslastung der Wasserstofftankstellen zu verbessern und nicht zuletzt die Wahrnehmung der Öffentlichkeit für brennstoffzellenbetriebene Fahrzeuge zu steigern und Vorurteile gegen diese neue Antriebstechnik abzubauen. Die zu erwartende hohe Auslastung der so eingesetzten Fahrzeuge ermöglicht außerdem schnellere Rückschlüsse auf das Verhalten dieser neuen Antriebssysteme im Verlauf der gesamten Nutzungsdauer von FCEV.

In München hat die dort ansässige Firma Linde ein Tochterunternehmen mit dem Namen Linde Hydrogen Concepts gegründet, um das Car-Sharing-System BeeZero mit FCEV aufzubauen [37]. Hierzu wurden 50 Hyundai ix35 Fuel Cell angeschafft, die seit August 2016 angemietet werden können und ausschließlich mit grünem Wasserstoff, also Wasserstoff, der zu $100 \%$ aus regenerativen Energiequellen erzeugt wird, betrieben werden [38]. Im Gegensatz zu bereits etablierten CarSharing-Formaten mit batterieelektrischen Fahrzeugen, wie dem Smart Electric Drive bei car2go oder dem BMW i3 bei Drive Now, zielt BeeZero nicht auf kurze, spontane Stadtfahrten ab, sondern stellt immissionsfreie Fahrzeuge für Wochenendausflüge oder längere Besorgungsfahrten zur Verfügung. Hierbei sind der größere Laderaum, die größere Reichweite und die fünf Sitzplätze im Hyundai klar von Vorteil [39].

Bei der Nutzung elektrisch betriebener Fahrzeuge durch Taxiunternehmen wirken sich die langen Ladezeiten von Batterien besonders negativ aus, da die Fahrzeuge so nicht mit mehreren Fahrern im 24-Stunden-Betrieb genutzt werden können, sondern mehrere Stunden täglich an Ladestationen verbringen müssen. In Paris hat das Start-up Step (Société du Taxi Electrique Parisien) im Dezember 2015 mit der Erprobung von FCEV für Taxifahrten begonnen und dazu fünf Hyundai ix35 Fuel Cell unter dem Namen Hype (Hydrogen Powered Electric) auf die Straßen gebracht (Bild 5) [40]. Wie im November 2016 bekannt wurde, wird diese Flotte nun um weitere 60 Fahrzeuge des gleichen Typs erweitert, wodurch Hype zur weltweit größten, brennstoffzellenbetriebenen Taxiflotte wird. Innerhalb der kommenden fünf Jahre soll diese Flotte auf mehrere Hundert Fahrzeuge ausgebaut werden und so ältere Taxis mit Verbrennungsmotor schrittweise ersetzen [41].

Während derzeit die Kernkomponente der meisten FCEV, der PEMFC-Stack, aus Japan oder Kanada kommt, werden in Europa und auch in Deutschland starke Anstrengungen unternommen, die Kernkompetenzen der Technik auch dort anzusiedeln. Als Resultat des im letztjährigen Bericht [1] vorgestellten EU-Projektes Autostack-Core bietet die schwedische Firma PowerCell Sweden AB jetzt den PEMFC-Prototypen-Stack S3 für den Automobilbereich mit einer Leistung von bis zu $100 \mathrm{~kW}$ an [42]. In Deutschland erscheint es so, dass nun ebenfalls verstärkte Bemühungen im Rahmen des NIP unternommen werden, die Fertigung von automobilen Brennstoffzellensystemen 
aufzubauen. So sagte Bundesverkehrsminister Alexander Dobrindt in einem am 15. Dezember 2016 in der Welt erschienen Artikel [43]: „Wir erleben international einen neuen Wettbewerb um den Antrieb der Zukunft. Mit im Zentrum steht dabei die Brennstoffzelle als eine Schlüsseltechnologie der Mobilität 4.0. Deutschland muss hier als Autoland Innovationsführerschaft übernehmen. Dazu gehört, dass wir die gesamte Wertschöpfungskette beherrschen. Wir brauchen eine eigene Brennstoffzellenproduktion für die Automobilindustrie in Deutschland und wir sind bereit, dieses Projekt mit Mitteln aus unserem Förderprogramm zu unterstützen."

In den vergangenen Jahren wurden die Zielsetzungen für die kommerzielle Einführung von PEMFC bezüglich Effizienz, Leistungsdichte und Kaltstartfähigkeit bereits erreicht [44]. Die Kosten der Systeme und ihre Lebensdauern müssen noch verbessert werden sowie eine Absenkung des Edelmetallgehaltes in Bereiche erfolgen, die bei Verbrennungsmotoren im Abgassystem verwendet werden (rund $3 \mathrm{~g}$ in Otto-Motoren und 6 bis $8 \mathrm{~g}$ in DieselMotoren). Damit würden die Kosten der Brennstoffzellen abgesenkt und die Nachfrage nach dem eingesetzten Edelmetallkatalysator Platin bei einer Marktdurchdringung nicht signifikant erhöht. Die Katalysatormengen in den Elektroden sollte daher auf deutlich unter $0,1 \mathrm{mg} /$ $\mathrm{cm}^{2}$ verringert werden. Da aufgrund der langsameren Kinetik der Sauerstoffreduk-

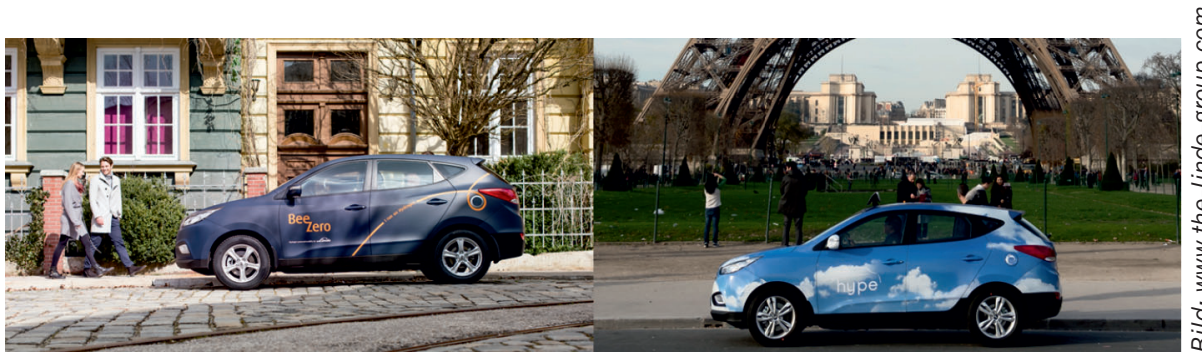

Bild 5 Hyundai ix35 Fuel Cell von BeeZero (links) und Hype. tion die Sauerstoffelektroden deutlich mehr Katalysatormaterial enthalten, ist vor allem die Reduktion der Beladung der Sauerstoffelektrode nötig, um die Kostenziele zu erreichen. Eine der interessantesten Neuentwicklungen wurde hierbei von General Motors im März 2016 veröffentlicht [45]. Bezüglich der Verringerung der Katalysatormenge in PEMFC besteht das Problem, dass bei Kathodenbeladungen im Bereich von $0,1 \mathrm{mg}-\mathrm{Pt} / \mathrm{cm}^{2}$ starke Leistungseinbußen bei hohen Stromdichten zu beobachten sind, während die Leistungsanforderungen bei geringen Stromdichten bereits erreicht werden können. Dieses Problem ist auf das Auftreten eines zusätzlichen Stofftransportwiderstandes in der Nähe des Katalysators zurückzuführen. Mit sinkender Beladung nimmt die verfügbare Katalysatoroberfläche $a b$, und die Sauerstofftransportrate zu dieser Oberfläche muss zunehmen, um die Reaktionsraten bei hohen Stromdichten zu gewährleisten. Hierdurch nimmt der lokale Transportwiderstand in der Nähe der Katalysatoroberfläche überproportional

\section{Trend 2017}

Für das Jahr 2017 ist zu erwarten, dass die Absatzzahlen von Mikro-KWK-Anlagen mit Brennstoffzellen für die Hausenergieversorgung aufgrund der deutlich attraktiveren Förderung über das TEP in Deutschland deutlich zunehmen. Auch Japan wird den Einsatz dieser Anlagen weiter vorantreiben, und die Marktdurchdringung ohne Subventionen scheint wahrscheinlich zu sein. Der Einsatz von Brennstoffzellen im Transportsektor wird ebenfalls zunehmen, und es bleibt abzuwarten, wie schnell sich dieser Sektor entwickeln kann. Dabei spielen nicht nur die Antriebe von Pkw und Bussen eine Rolle. Auch die Entwicklung bei Zügen und Schiffen geht hin zur Erprobung der Systeme im realen Betrieb. Durch die Möglichkeit, Wasserstofftanksäulen direkt in konventionelle Tankstellen zu integrieren, sind auch die zu erwartenden Kosten für den Ausbau der Tankinfrastruktur gesunken, und für 2017 ist weltweit ein deutlicher Ausbau zu erwarten. Dabei wird sich der Ausbau auf Tankstellen in Ballungszentren konzentrieren, die dann über so genannte Hydrogen Highways miteinander verbunden werden. Die Entwicklung und Verbreitung der Wasserstofftechnologien wird derzeit in Asien am stärksten vorangetrieben. Neben Japan, das die Olympischen Spiele als Schaufenster für diese Technologien nutzen will, verstärkt China seine Anstrengungen massiv, um im Elektromobilitätsbereich und auch bei den Wasserstofftechnologien eine führende Rolle zu übernehmen. In 2017 werden sich die zunehmenden Kooperationen mit amerikanischen Marktführern der Wasserstoffbranche noch intensivieren, und China wird die Produktion von Wasserstofftechnologien im eigenen Land stetig vorantreiben. Des Weiteren wird im kommenden Jahr die zunehmende Nutzung von Synergieeffekten zwischen Wasserstoff- und konventionellen Technologien im Vordergrund stehen, um die stoffliche Nutzung in verschiedenen Industriesektoren und die energetische Gesamteffizienz der Wasserstoffanlagen zu steigern. zu. Dieser lokale Transportwiderstand ist auf die Sauerstoffdiffusion durch den Ionomerfilm auf der Katalysatorfläche zurückzuführen. Um dem Problem entgegenzutreten, müssen zum einen Katalysatoren mit großen Oberflächen bei geringem Katalysatoreinsatz realisiert werden, die auch im Brennstoffzellenbetrieb stabil sind, und zum anderen spezielle Ionomere mit hoher Sauerstoffpermeabilität für die Verwendung in der Katalysatorschicht entwickelt werden. Durch die identifizierten Verbesserungspotenziale erscheint es nun möglich, die Leistungsfähigkeit der Brennstoffzelle mit geringer Katalysatorbeladung auch bei hohen Stromdichten zu gewährleisten. Hierzu ist jedoch weitere Materialentwicklung beim Katalysator und bei den in den Elektroden eingesetzten Ionomeren nötig. Wie in der Veröffentlichung von General Motors gezeigt wurde, könnten die Stackkosten durch die Umsetzung von Elektrodenstrukturen mit niedrigen lokalen Sauerstofftransportwiderständen um bis zu $25 \%$ reduziert und so die Ziele für eine Kommerzialisierung erreicht werden.

\section{Weitere mobile}

\section{Brennstoffzellenanwendungen}

Bereits im letzten Jahr wurde berichtet, dass die Alstom Transport Deutschland GmbH in Zusammenarbeit mit Hydrogenics, Xperion und Akasol ein Triebfahrzeugkonzept für die Schiene entwickelt, das Brennstoffzellen und Wasserstoff zur Energieversorgung für nicht elektrifizierte Regionalstrecken nutzt [1]. Im September 2016 hat Alstom nun den Coradia iLint (Bild 6) auf der Bahntechnikmesse InnoTrans in Berlin vorgestellt [46]. Dieser emissionsfreie Nahverkehrszug für 300 Passagiere erreicht Geschwindigkeiten von $140 \mathrm{~km} / \mathrm{h}$. Durch die Hybridisierung der NT-PEMFC-Systeme mit leistungsstarken Lithium-Ionen-Batterien und der Energierückgewinnung beim Abbremsen des Zuges können mit einer Tankfüllung 600 bis $800 \mathrm{~km}$ zurückgelegt sowie die gesamte Bordversorgung mit Elektrizität gewährleistet werden. Alstom 


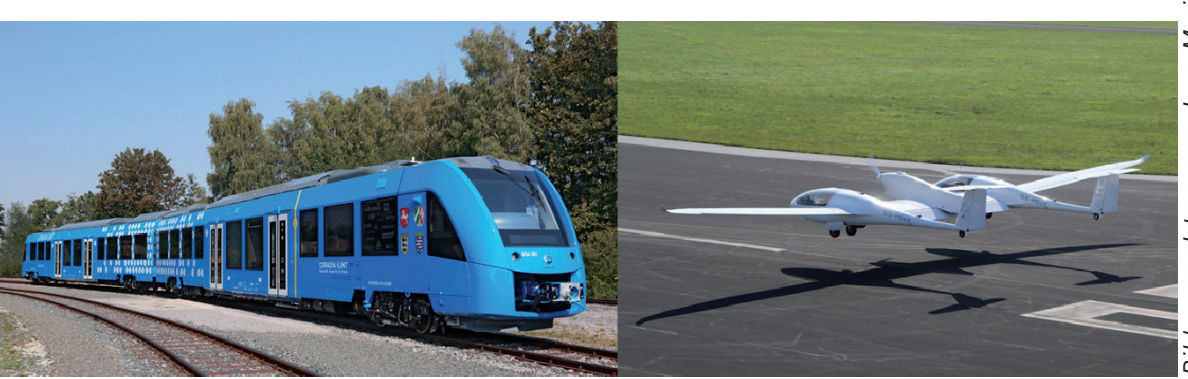

Bild 6 Brennstoffzellenzug Coradia iLint von Alstom (links) und 4-sitziges Brennstoffzellenflugzeug HY4.

bietet zusammen mit seinen Partnern für die Betreiber neben dem Zug auch dessen Instandhaltung und den Aufbau der benötigten Wasserstoffinfrastruktur an [47]. Gerade der Aufbau der Wasserstoffversorgung stellt auch auf der Schiene eine wichtige Voraussetzung für die Einführung der Technologie in größeren Stückzahlen dar. Der Coradia iLint wird in Salzgitter gefertigt, und bislang stehen zwei Prototypen zur Verfügung, die sich zurzeit im Zulassungsverfahren beim Eisenbahn-Bundesamt (EBA) befinden. Ab dem Dezember 2017 sollen die beiden Züge dann auf der Bahnstrecke zwischen Buxtehude und Cuxhaven erprobt werden [48]. Insgesamt hat die Landesnahverkehrsgesellschaft Niedersachsen bereits 14 Exemplare des Coradia iLints bestellt, und die Bundesländer Baden-Württemberg, Hessen und Nordrhein-Westfalen haben entsprechende Absichtserklärungen unterzeichnet. Insgesamt ist bis 2021 der Betrieb von 60 Zügen in den vier Bundesländern geplant [49].

Auch die im NIP geförderte Entwicklung des viersitzigen Brennstoffzellenflugzeugs HY4 wurde im vergangenen Jahr abgeschlossen (Bild 6). Der HY4 wurde vom Institut für Technische Thermodynamik des DLR (Deutsches Zentrum für Luftund Raumfahrt e. V.) zusammen mit Hydrogenics, Pipistrel, H2Fly, der Universität Ulm und dem Flughafen Stuttgart entwickelt, und der offizielle Erstflug erfolgte am 29. September 2016 am Flughafen in Stuttgart [50]. Dabei handelt es sich um das weltweit erste, viersitzige Passagierflugzeug, das alleine von einem Brennstoffzellenhybridsystem angetrieben wird. Das System beinhaltet vier PEMFC-Systeme mit einer Leistung von $45 \mathrm{~kW}$ sowie Lithium-Ionen-Batterien mit einer Leistung von $45 \mathrm{~kW}$ und einer Kapazität von $21 \mathrm{kWh}$. Diese treiben den $80 \mathrm{~kW}$ starken Elektromotor des $1500 \mathrm{~kg}$ schweren HY4 an, der so eine Richtgeschwindigkeit von $165 \mathrm{~km} / \mathrm{h}$ und eine Maximalgeschwindigkeit von $200 \mathrm{~km} / \mathrm{h}$ erreicht. Durch die mitgeführten $9 \mathrm{~kg}$
Wasserstoff in den beiden in die Rümpfe integrierten Wasserstofftanks können je nach Geschwindigkeit, Flughöhe und Zuladung Reichweiten von 750 bis $1500 \mathrm{~km}$ realisiert werden. Der HY4 stellt für das DLR und seine Partner eine wichtige Entwicklungsplattform für brennstoffzellenbetriebene Flugzeuge dar, die perspektivisch die Weiterentwicklung von Regionalflugzeugen mit bis zu 19 Passagieren ermöglichen soll. Diese Entwicklung ist Teil der mehr als zehnjährigen Arbeit des DLR im Bereich des elektrischen Fliegens, um die große Herausforderung, die Elektromobilität auch in die Luftfahrt zu integrieren und so den Luftverkehr zunehmend $\mathrm{CO}_{2}$-neutral zu gestalten, umsetzen zu können.

Im Abschlussbericht des FCH-JU geförderten Projektes Chic (Clean Hydrogen in European Cities, 2010 bis 2016) wurde im Dezember 2016 ein Überblick über die weltweiten Fortschritte des Aufbaus von wasserstoffbetriebenen Busflotten veröffentlicht [51]. Demnach befanden sich Ende 2016 insgesamt 109 Busse im Betrieb, und die Inbetriebnahme von über 700 weiteren Bussen ist in den kommenden Jahren geplant. Die Verteilung der brennstoffzellenbetriebenen Busflotte auf die verschiedenen Länder ist in Bild 7 zusammengefasst, wobei man erkennt, dass gerade in Europa, China, Japan und Südkorea ein starker Zuwachs in den kommenden Jahren zu erwarten ist.

Bis Ende 2016 befanden sich in Europa 58 Busse im Betrieb, und weitere 167 sind für die kommenden Jahre geplant. Einen großen Anteil an der geplanten Inbetriebnahme neuer Busse hat das vom FCH JU geförderte Projekt JIVE (Joint Initiative for hydrogen Vehicles across Europe), das im Januar 2017 startete. In diesem Projekt sollen durch die Kooperation von 24 Partnern bis 2022 insgesamt 142 Brennstoffzellenbusse an neun verschiedenen Orten in Betrieb genommen werden. Die Busse werden in größeren Flotten zu 10 bis 30 Fahrzeugen in Deutschland (Köln und Wuppertal), Großbritannien (London,
Birmingham, Dundee und Aberdeen), Italien (Südtirol), Lettland (Riga) und Dänemark (Slagelse) in den ÖPNV integriert. Begleitend zu dem Aufbau dieser Flotten soll in Zusammenarbeit mit dem Projekt Mehrlin (Models for Economic Hydrogen Refuelling Infrastructure) auch der Aufbau von sieben Wasserstofftankstellen realisiert werden, die den hohen täglichen Wasserstoffbedarf der Flotten abdecken können [52]. Das Mehrlin-Projekt (2016 bis 2020) ist eine Kooperation von zehn Partnern und wird vom Programm European Commission's Connecting Europe Facility gefördert.

Aufgrund der im maritimen Sektor häufig eingesetzten Brennstoffe Schweröl und Schiffsdiesel sind hier die Emissionen an Stickoxiden, Schwefeloxiden und Feinstaubpartikeln besonders hoch, und aufgrund der immer strenger werdenden Regularien und der Tatsache, dass $90 \%$ aller Gütertransporte durch Schiffe erfolgen, ist die Entwicklung emissionsarmer Antriebsysteme für Schiffe von besonderem Interesse. Die im Januar 2017 erschienene "Study on the Use of Fuel Cells in Shipping" von der European Maritime Safety Agency (EMSA) hat die Ergebnisse von insgesamt 23 Brennstoffzellenprojekte der vergangenen Jahre auf dem maritimen Sektor zusammengefasst und kommt zu dem Schluss, dass die Brennstoffzellentechnologie als alternative Schiffsantriebe von besonderem Interesse ist und sich die eingesetzte Technologie vor allem nach der Größe der Systeme richtet [53]. Bei Systemen zur Bordenergieversorgung und zum Antrieb kleinerer Passagierbote mit Leistungen bis $100 \mathrm{~kW}$ sind Niedertemperaturbrennstoffzellen vorteilhaft, während bei der Energieversorgung von großen Containerschiffen bis $650 \mathrm{~kW}$ Hochtemperaturbrennstoffzellen zum Einsatz kommen können. Im Rahmen der internationalen Messe für die Schifffahrtindustrie (SMM) wurden im September 2016 die Ergebnisse der ersten Phase von e4ships und damit der vom NIP geförderten Brennstoffzellenaktivitäten in Deutschland vorgestellt [54]. Unter anderem wurde im von der Meyer-Werft geführten Teilprojekt Pa-X-ell ein methanolbetriebenes 90-kW-System auf der Skandinavien-Fähre MS Mariella installiert. Das System besteht aus drei standardisierten Racks von fischer eco solutions und SerEnergy mit jeweils sechs luftgekühlten HT-PEMFC-Modulen, die eine elektrische Leistung von $5 \mathrm{~kW}$ liefern und einen internen Methanolreformer besitzen. Im von der Thyssenkrupp Marine 
Systems geführten Teilprojekt SchIBZ werden dieselbetriebene SOFC-Systeme mit skalierbaren Leistungen zwischen 100 und $500 \mathrm{~kW}$ als Hauptenergie für die Stromversorgung von Hochseeschiffen entwickelt. In der ersten Projektphase wurde ein 50-kW-Demonstrator für die Erprobung unter realen Bedingungen auf der MS Forester installiert. Die Langzeiterprobung und Weiterentwicklung der Demonstratoren soll nun in einer zweiten Phase im Rahmen des erweiterten NIP bis 2022 erfolgen.

Bereits seit 2006 bietet die in München ansässige Firma Smart Fuel Cell Energy mobile Brennstoffzellensysteme für die Energieversorgung von Wohnmobilen, Booten und Ferienhäusern abseits des Stromnetzes an. Die dazu angebotene Efoy-Brennstoffzelle ist eine Direktmethanolbrennstoffzelle (DMFC, Direct Methanol Fuel Cell), die das flüssige Methanol ohne vorherige Reformation direkt zur Ladung von mitgeführten Batterien nutzt. Im Januar 2016 feierte die EfoyBrennstoffzelle ihren zehnten Geburtstag, und seit ihrer Einführung wurden weltweit über 34000 Geräte verkauft [55]. Das damit am weitesten verbreitete Brennstoffzellensystem zur mobilen Energieversorgung wird mittlerweile in fünf verschiedene Varianten mit elektrischen Leistungen zwischen 25 und $90 \mathrm{~W}$ angeboten, die Ladekapazitäten zwischen 600 und $2160 \mathrm{Wh} / \mathrm{d}$ bereitstellen. Die Brennstoffversorgung erfolgt über 28-, 10- und 5-1-Tankpatronen mit einer Kapazität von 31,11 beziehungsweise $5,5 \mathrm{kWh}$. Weltweit können die Efoy-Systeme sowie die Tankpatronen bei einer Vielzahl an Händlern, wie beispielsweise im Campingfachhandel, und auch über den Online-Handel erworben werden. Alleine in Deutschland sind etwa 250 Händler gelistet.

\section{Entwicklung der Tankstelleninfrastruktur zur Wasserstoffbetankung}

Die Tankstelleninfrastruktur wird weiterhin weltweit ausgebaut, um die Verfügbarkeit von Wasserstoff für den Transportsektor zu verbessern und die Vorteile von lokaler Emissionsfreiheit von Wasserstoffantrieben, deren größere Reichweite und deren schnelle Betankung zunehmend nutzen zu können. Wie die neunte Jahresauswertung der Standorte von Wasserstofftankstellen auf H2stations.org von LBST (Ludwig-Bölkow-Systemtechnik) und dem TÜV Süd ergab, wurden in 2016 weltweit 92 Tankstellen, davon 83 öffentlich zugängliche, neu eröffnet [56]. Der
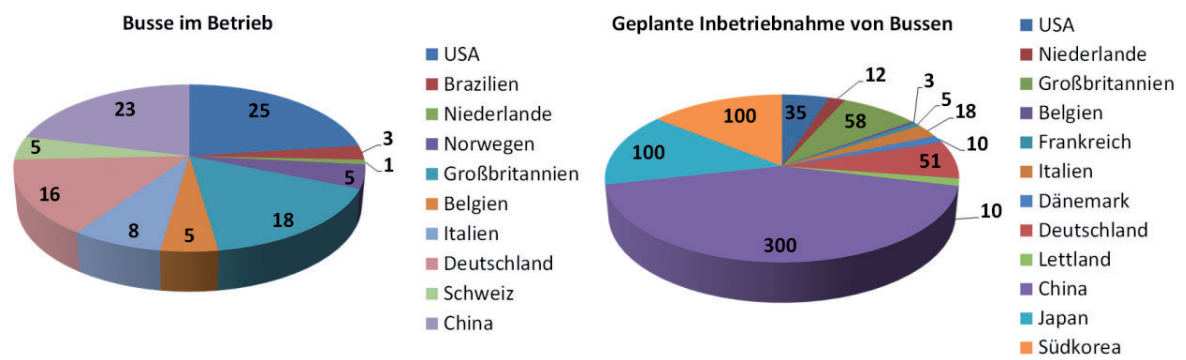

Bild 7 Ende 2016 in Betrieb befindliche (links) sowie weitere geplante Brennstoffzellenbusse.
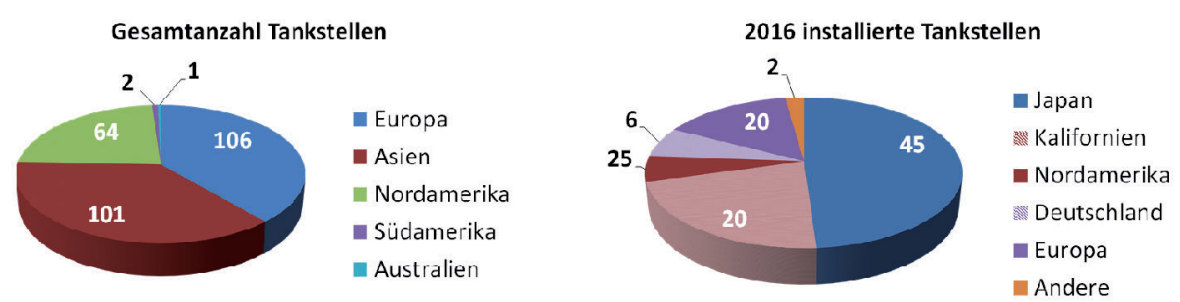

Bild 8 Ende 2016 in Betrieb befindliche (links) sowie in 2016 neu installierte Wasserstofftankstellen.

überwiegende Teil des Ausbaus der Infrastruktur entfällt dabei auf Japan mit 45, Nordamerika mit 25 (davon 20 in Kalifornien) und Europa mit 20 (davon sechs in Deutschland) neuen Tankstellen. Bis Ende 2016 waren insgesamt 270 Tankstellen in Betrieb, von denen ungefähr zwei Drittel öffentlich zugänglich sind. Bei der Analyse der Standorte ergab diese Auswertung, dass sich von den Tankstellen 106 in Europa, 101 in Asien, 64 in Nordamerika, zwei in Südamerika und eine in Australien befinden. Die Verteilung der weltweit bislang aufgebauten sowie der in 2016 neu errichteten Wasserstofftankstellen ist in Bild 8 grafisch dargestellt.

Seit der letzten Jahresübersicht Wasserstoff und Brennstoffzellen im Mai 2016 [1] wurden in Deutschland mehrere neue Möglichkeiten zur Wasserstoffbetankung geschaffen, deren Wasserstoffversorgung durch Anlieferungen aus verschiedenen Quellen realisiert werden. Der Ausbau dieser Infrastruktur erfolgt in Deutschland unter der Federführung der H2 Mobility Deutschland GmbH \& Co. KG, der Initiative Wasserstoff Brennstoffzelle Deutschland, der CEP (Clean Energy Partnership) sowie deren Partnern und wird vom NOW (Nationale Organisation Wasserstoff- und Brennstoffzelle) im NIP und NIP2 unterstützt und vom BMVI gefördert.

Zunächst wurden im Juli 2016 gleich zwei neue Anlagen eröffnet. Dabei handelt es sich um eine reine WasserstoffTankstelle am ZSW (Zentrum für Sonnenenergie- und Wasserstoff-Forschung Baden-Württemberg) in der Ulmer Helm- holzstraße, die von Daimler, Linde und Total zusammen mit dem ZSW aufgebaut wurde [57], und einer Wasserstoffzapfsäule, die in die bestehende, konventionelle Shell-Tankstelle in Wuppertal direkt an der Abfahrt Wuppertal-Oberbarmen der A1 integriert wurde [58]. Im September 2016 folgte dann die Aufrüstung der OMV-Station Auchtertstraße in Metzingen durch Daimler, Linde und OMV um eine 700-bar-Wasserstofftanksäule [59]. Im November 2016 wurde eine weitere Wasserstofftankstelle in Offenbach am Main der Öffentlichkeit übergeben. Diese Tankstelle auf dem Gelände der HyundaiZentrale in der Kaiserleipromenade war bis dahin nur den Hyundai-eigenen Fahrzeugen zugänglich, wurde nun aber zusammen mit Air Liquide zu einer öffentlichen Tankstelle mit einer täglichen Wasserstoffkapazität von $200 \mathrm{~kg}$ umgerüstet [60]. Im Dezember 2016 wurden zwei weitere Erweiterungen von konventionellen Tankstellen eröffnet. So wurde von Linde die Shell-Tankstelle in Kirchenhausen im Landkreis Tuttlingen um eine $\mathrm{H}_{2}$-Tanksäule ausgebaut [61], und an der Tankstelle der Westfalen AG im Industriegebiet Hansa-Business-Park in der Kopenhagener Straße in Münster-Amelsbüren wurden mit je einer Tanksäule für 350 und 700 bar Möglichkeiten zur Betankung von Pkw und Bussen geschaffen [62]. Im Januar 2017 folgten dann die zwei bislang neuesten Erweiterungen des Wasserstofftankstellen-Netzwerkes in Deutschland. Linde hat in Unterschleißheim ihre Testund Entwicklungstankstelle zu einer öffentlichen Betankungsmöglichkeit um- 

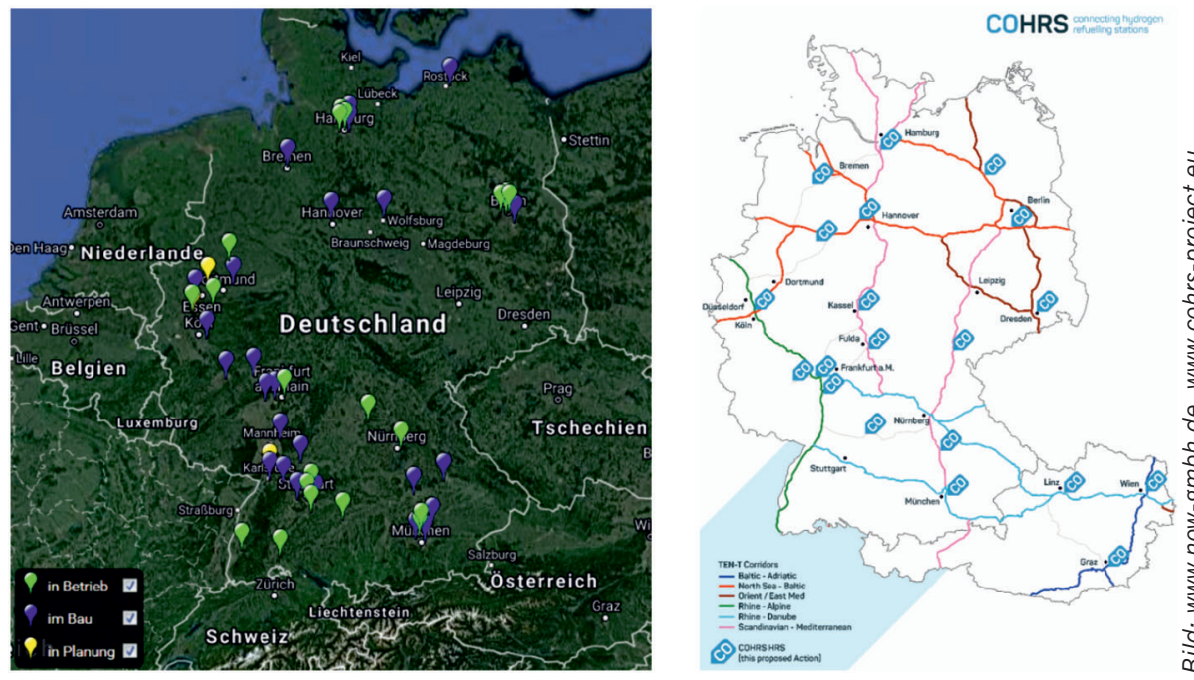

Bild 9 Aufbau von Wasserstofftankstellen in Deutschland (links) und über das Cohrs-Projekt.

gerüstet [63] und in Kamen wurde von Linde die erste Wasserstofftankstelle im Ruhrgebiet eröffnet [64]. Bis Ende Januar 2017 ist das Wasserstofftankstellennetzwerk in Deutschland damit auf 25 öffentlich zugängliche Tankstellen angewachsen. Das hochgesteckte Ziel von 50 Tankstellen bis Ende 2016 konnte somit zwar nicht erreicht werden, aber laut der interaktiven Planungskarte des NOW (Bild 9) befinden sich bereits 25 neue Projekte im Bau und drei Wasserstofftankstellen in der Planungsphase [65]. Zwei weitere Tankstellen sind dabei bereits kurz von der Eröffnung. Der von Air Liquide realisierte Aufbau der Tankstelle in Limburg mit einer Tageskapazität von $200 \mathrm{~kg}$ Wasserstoff wurde Ende Januar 2017 bereits abgeschlossen, die Anlage befindet sich allerdings aktuell noch im 6-wöchigen Testbetrieb [66]. Die erste Wasserstoff-Station in Mecklenburg-Vorpommern entsteht derzeit im Rahmen des Baus der Total-Multi-Energie-Tankstelle in Rostock. Diese Tankstelle bietet den Zugang zu konventionellen Treibstoffen, Elektroladestationen und Wasserstoffzapfsäulen an und soll noch im Frühjahr 2017 eröffnet werden [67].

Während sich die nationalen Förderprogramme zum Aufbau von Wasserstofftankstellen in Europa zunächst im Wesentlichen auf Ballungszentren konzentrieren, fokussiert sich das Projekt Cohrs (Connecting Hydrogen Refuelling Stations) auf die Verbindung der so entstandene Korridore mit bereits entwickelter Infrastruktur und die Bereitstellung von Wasserstoffbetankungsmöglichkeiten entlang der transeuropäischen Transportrouten (TEN-T, trans-european transport network) [68]. Dieses europäische
Projekt wird von der Inea (Innovation and Networks Executive Agency) gefördert und soll zwischen September 2015 und Juni 2019 durch die Installation von 20 $\mathrm{H}_{2}$-Tankstellen in Österreich und Deutschland die Vernetzung der bestehenden Korridore ermöglichen (Bild 9). Die erste Tankstelle aus diesem Projekt wurde im September 2016 in Asten bei Linz in Österreich von der OMV eröffnet und liegt direkt an der Westautobahn A1, einer der wichtigsten europäischen Verbindungsachsen [69]. Dabei handelt es sich um die dritte, öffentlich zugängliche $\mathrm{H}_{2}$-Tankstelle in Österreich neben den beiden OMV-Standorten Wien und Innsbruck. Im März 2017 folgte dann die Eröffnung der zweiten Cohrs- und vierten österreichischen Tankstelle durch OMV in Graz direkt an der Südautobahn A 2 [70].

Auch in der Schweiz wurde die erste, öffentliche Wasserstofftankstelle im November 2016 in Hunzenschwil eröffnet [71]. Die Tankstelle wird vom Handelskonzern Coop-Logistik betrieben und mit Wasserstoff versorgt, der im nahegelegenen Wasserkraftwerk der IBAarau von der $\mathrm{H} 2$ Energy AG $\mathrm{CO}_{2}$ - und schadstofffrei durch Elektrolyse erzeugt wird. Angeboten werden Tankmöglichkeiten mit 350 und 700 bar, und Coop-Logistik hat parallel zur Eröffnung zwölf Hyundai-ix35Fuel-Cell-Firmenwagen und den weltweit ersten Wasserstoff betriebenen Lastwagen mit Anhänger für den Lieferverkehr in die eigenen Fahrzeugflotte aufgenommen.

Neben der direkten Verwendung von Wasserstoff als Treibstoff für FCEV kann auch Methanol in Brennstoffzellensystemen, wie beispielsweise als Range Extender im erwähnten Prototyp auf Basis des Fiat e500, umgesetzt werden. Zur Versor- gung dieser Prototypen, hat im August 2016 SerEnergy, OK und Hamag auch die erste europäische Methanol-Tankstelle im dänischen Aalborg eröffnet [72]. An dieser Tankstelle wird ausschließlich umweltfreundlich erzeugtes Methanol angeboten, das von der Carbon Recycling International (CRI) in Island unter dem Namen Vulcanol erzeugt wird, indem $\mathrm{CO}_{2}$ aus industriellen Abgasen mit aus erneuerbaren Energien erzeugtem Wasserstoff umgesetzt wird. Der Wasserstoff als Energieträger spielt also auch bei dieser Anwendung eine wichtige Rolle, wird allerdings noch in Methanol überführt, das als flüssiger Brennstoff den Vorteil der höheren Energiedichte besitzt und leichter in die bestehende Infrastruktur für flüssige Treibstoffe integriert werden kann.

\section{Wasserstofferzeugung aus erneuerbaren Energien und deren Nutzung}

Nach erfolgreicher Testphase hat im Oktober 2016 der so genannte Windgas-Elektrolyseur im bayrischen Haßfurt (Bild 10) den Regelbetrieb aufgenommen, ein Projekt, das ohne öffentliche Fördermittel realisiert wurde [73]. Diese ElektrolyseAnlage wird von den Städtischen Betrieben Haßfurt und dem Hamburger Ökostromanbieter Greenpeace Energy über die gemeinsame Windgas Haßfurt GmbH \& Co. KG betrieben und wandelt Überschussstrom aus dem Windpark Sailershäuser Wald in bis zu $225 \mathrm{~m}^{3}$ (i.N.)/h Wasserstoff um, der direkt ins Erdgasnetz eingespeist wird. Die Umwandlung erfolgt in dem 1,25 MW starken PEM-Elektrolyseur Silyzer 200 von Siemens, und der eingespeiste Wasserstoff wird von Greenpeace Energy im Gastarif proWindgas privaten Kunden zur Verfügung gestellt. Neben der energetischen Nutzung des regenerativ erzeugten Wasserstoffs dient die installierte Windgas-Anlage auch der Frequenzstabilisierung und verhindert Ausfälle im lokalen Stromnetz, indem Stromerzeugung und Verbrauch durch die Primärregelleistung des Elektrolyseurs im Gleichgewicht gehalten werden. Durch eine von Next Kraftwerk entwickelte Steuerungssoftware wird der Elektrolyseur hierzu mit anderen Anlagen zu einem virtuellen Kraftwerk verschaltet und die Stromaufnahme des Elektrolyseurs kann innerhalb von Millisekunden an die Menge an bereitgestellter elektrischer Energie angepasst werden.

Im Rahmen des vom dänischen ForskEL-Programm geförderten BioCat-Projektes (Power-to-Gas via Biological Catalysis) 
wurde zwischen Februar 2014 und Oktober 2016 eine Elektrolyseanlage in Avedore (Dänemark) aufgebaut, die verschiedene Synergieeffekte der Elektrolysetechnik eindrucksvoll demonstriert [74]. Der integrierte, alkalische S1000-Elektrolyseur von Hydrogenics mit einer elektrischen Leistung von $1 \mathrm{MW}$ ist an das lokale Stromnetz angeschlossen und trägt zur Frequenzstabilisierung des Netzes bei. Der erzeugte Wasserstoff (bis $\mathrm{zu} 200$ $\mathrm{m}^{3}(\mathrm{i} . \mathrm{N}$.)/h) wird stofflich genutzt, indem er einem biologischen Methanisierungsreaktor von Electrochaea zugeführt und darin mit $\mathrm{CO}_{2} \mathrm{zu}$ Methan umgesetzt wird. Die Umsetzung wird in diesem Flüssigphasen-Bioreaktor durch Archeabakterien ermöglicht, und das entstehende Methan wird dann dem Erdgasnetz zugeführt. Besonders interessant ist die Tatsache, dass in dieser Anlage nicht nur der elektrolytisch erzeugte Wasserstoff stofflich genutzt wird, sondern auch der ebenfalls bei der Elektrolyse entstehende Sauerstoff vor Ort Verwendung findet. Das Projekt wurde in Avedore auf dem Gelände der Biofos-Abwasserkläranlage realisiert (Bild 10), und der Sauerstoff wird dort dem Belebungsbecken zugeführt, um organische Bestandteile im Abwasser $\mathrm{zu}$ oxidieren und so $\mathrm{zu} \mathrm{CO}_{2}$ abzubauen. Die gesamte Anlage ist seit Juni 2016 im Betrieb.

Im Dezember 2016 hat Proton OnSite in Shanghai einen Vertrag mit der Guangdong Synergy Hydrogen Power Technology zur Lieferung von 13 PEM-ElektrolyseAnlagen mit einer elektrischen Leistung von je $1 \mathrm{MW}$ unterzeichnet, die den Wasserstoff für brennstoffzellen-betriebene Busse in den Städten Foshan und Yunfu erzeugen sollen [75]. Drei Anlagen sollen bereits im Sommer 2017 geliefert werden, und zehn weitere sollen innerhalb von 18 Monaten folgen. Die Kooperation der beiden Firmen soll danach durch die Produktion von Proton-OnSite-Elektrolyseuren der M-Serie in Foshan fortgeführt werden. Guangdong Synergy Hydrogen Power Technology hat zudem im Oktober 2016 einen Vertrag zur Lieferung von mehr als 300 FCvelocity-HD-Brennstoffzellensystemen von Ballard Power Systems unterzeichnet sowie die Fertigung von BallardSystemen in China lizenziert [76]. Durch die beiden Kooperationen stellt Guangdong Synergy Hydrogen Power Technology in China die Weichen für das weltweit größte Programm für mit regenerativ erzeugtem Wasserstoff betriebene Brennstoffzellenbusse, das in den kommenden Jahren realisiert werden soll.

Bild 10 Windgas-Anlage in Haßfurt (oben) und BioCat-Anlage in Avedore.

Wie auch dieser Bericht wieder aufzeigt, besitzt Japan derzeit eine Vorreiterrolle bei der Weiterentwicklung der Wasserstofftechnologien und deren Nutzung im Energie und Transportsektor. Eine Tatsache, die durch die Bereitschaft, diese Technologien massiv zu fördern, zurückzuführen ist. Japan ist das Land mit dem dichtesten Netzwerk an

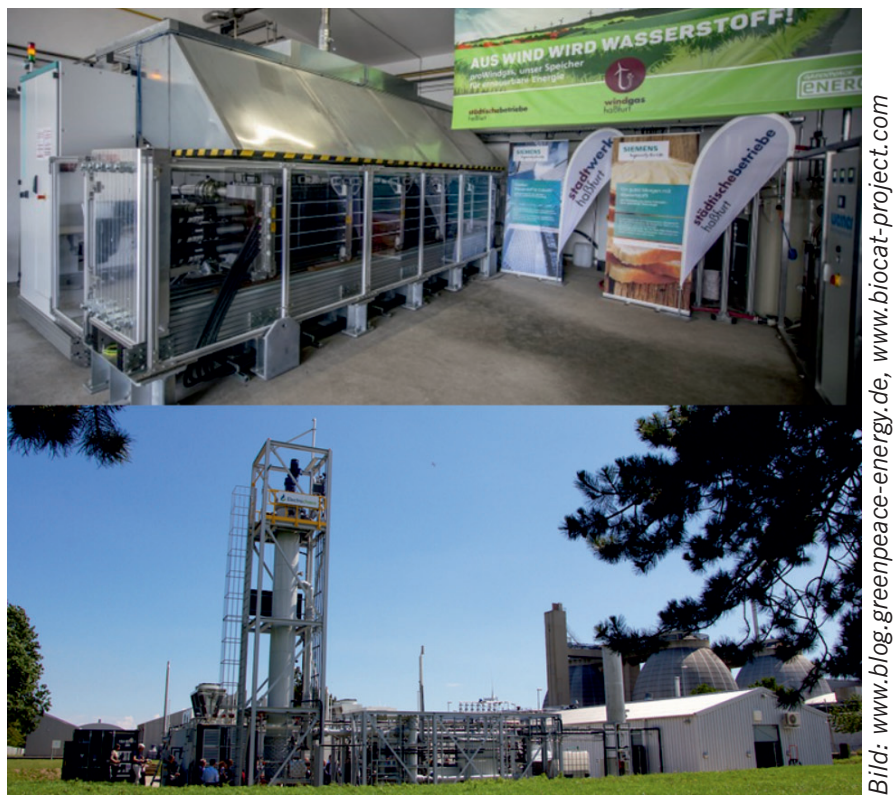
Wasserstofftankstel-

len, und mit Toyota und Honda sind gleich zwei Hersteller von kommerziell erhältlichen FCEV in Japan ansässig. Auch die Absatzzahlen von Mikro-KWK-Anlagen auf Brennstoffzellenbasis sind in Japan mit Abstand am höchsten. Mit Blick auf die Olympischen Spiele 2020 in Tokyo will Japan die Marktreife der verschiedenen Wasserstofftechnologien demonstrieren, und wie im März 2016 bekanntgegeben wurde, soll in diesem Kontext auch das größte Zentrum für Wasserstoffproduktion in Fukushima aufgebaut werden [77]. Nach der Atomkatastrophe in 2011 hat Japan den Wandel in der Energieversorgung hin $\mathrm{zu}$ sicheren, regenerativen Energiequellen stark fokussiert und baut dabei wesentlich auf die Nutzung von Wasserstoff als Energieträger. Mit dem Ausbau der Wasserstoffproduktion in Fukushima soll auch der Ort des Störfalles ein Beispiel für die Nutzung regenerativer Energiequellen werden. Hierzu soll unter dem Namen „Fukushima new energy society initiative“ in der Region Naraha die Nutzung von Windkraft zur Energieerzeugung und der Wasserstoffproduktion über Elektrolyse zur Energiespeicherung und -verteilung massiv ausgebaut werden. Bis 2020 soll so die Wasserstoffbereitstellung für bis zu 10000 FCEV über $10 \mathrm{MW}$ Elektrolyseleistung und deren effiziente Verteilung über verflüssigten Wasserstoff bereitgestellt werden, um das Olympische Dorf und die Beförderung der Athleten zu gewährleisten.

\section{Synergetische Nutzung von} Wasserstoff- und Stromerzeugung Das Großprojekt $\mathrm{H}_{2}$ Orizon ist ein Gemeinschaftsprojekt des Deutschen Zen- trums für Luft- und Raumfahrt (DLR), der ZEAG Energie AG und Air Liquide, das vom Land Baden-Württemberg gefördert wird und eine technologieoffene Demonstrations- und Forschungsplattform für ein breites Spektrum von Wasserstofftechnologien bietet [78]. Für diese Technologieplattform stehen am DLR-Standort Lampoldshausen ein 2,5 ha großes Gelände zur Verfügung, auf dem eine regenerative Wasserstoffprozesskette entwickelt wird, um so alle Teilprozesse der Nutzung von Wasserstoff als Energieträger abzubilden (Bild 11). Dies umfasst sowohl die Wasserstofferzeugung, die Speicherung und den Transport des Wasserstoffs als auch dessen Nutzung in den Sektoren Raumfahrt, Energie und Verkehr sowie die Nutzung von Synergieeffekten zwischen den verschiedenen Sektoren.

Die Wasserstofferzeugung erfolgt am DLR-Standort Lampoldshausen in vier PEM-Elektrolysestacks des englischen Herstellers ITM Power mit einer gesamten Nennleistung von $1 \mathrm{MW}$ und einer Wasserstoffproduktionsrate von $6,3 \mathrm{~kg} / \mathrm{h}$. So sollen jährlich 20 bis $40 \mathrm{t}$ Wasserstoff erzeugt werden. Gespeist wird die Elektrolyseanlage mit elektrischer Energie aus dem Ende 2015 fertiggestellten Windpark Harthäuser Wald der ZEAG Energie AG. Um den so bei 20 bar erzeugten Wasserstoff für alle Sektoren nutzbar zu machen, wird dieser vor Ort auf eine Reinheit von 5.0 aufbereitet und auf 350 bar verdichtet [79]. Aufgrund des hohen Wasserstoffbedarfs des DLR-Standorts Lampoldshausen, an dem unter anderem auch alle Triebwerke der Ariane 5 getestet werden, stehen bereits große Speicherkapazitäten für kryogenen und gasförmigen Wasser- 
stoff zur Verfügung. Vor Ort wird der Wasserstoff zum Betrieb von Prüfständen für Raumfahrtantriebe genutzt. Zusätzlich wird ein Blockheizkraftwerk mit einer elektrischen Leistung von 1,4 MW und einer thermischen Leistung von 1,6 MW errichtet, das die Grundlast des Standorts abdecken soll. In diesem Blockheizkraftwerk soll neben dem Betrieb mit Erdgas auch die Beimischung von Wasserstoff als Brennstoff untersucht werden, um so das Erdgasnetz als Möglichkeit der Wasserstoffverteilung zu untersuchen. Der Wasserstoff kann auch über Tube-Trailer an verschiedene Bedarfsorte in der Region verteilt werden und so in verschiedenen, industriellen Anwendung zum Einsatz kommen. Auch der Aufbau einer Wasserstofftankstelle für die Nutzung des Wasserstoffs im Transportsektor ist angedacht. Derzeit befindet sich die gesamte Anlage im Aufbau und soll Ende 2017 in Betrieb genommen werden.

SOFC haben in den vergangen Jahren bereits ihre hohe Effizienz und ihre hohe Lebensdauer bei der stetigen Umsetzung von Wasserstoff in elektrische Energie in stationären Anwendungen demonstriert und haben beispielsweise in verschiedenen Mikro-KWK-Anlagen bereits die Marktreife erreicht. Im Unterschied zu anderen Brennstoffzellentypen ist es bei dieser SOFC-Technik nun gelungen, Stacks zu entwickeln, die sowohl im Brennstoffzellen- als auch im Elektrolysebetrieb arbeiten können und somit die Umwandlung von elektrischer Energie in chemische Energie in Form von Wasserstoff reversibel gewährleisten können. Man spricht dann von reversiblen Festoxidelektrolyseuren (RSOC, Reversible Solid Oxide Electrolysers), die es ermöglichen, die Investitionskosten für die elektrochemische Zwischenspeicherung von elektrischer Energie deutlich zu verringern, da für die beiden Aufgaben keine getrennten Anlagen installiert werden müssen. Die dazu benötigten RSOC-Systeme werden mittlerweile von der in Dresden ansässigen Sunfire GmbH angeboten. Im Februar 2016 hat Sunfire die weltweit

Bild 12 RSOC-Anlage von Sunfire in Kalifornien (links) und Vorteile der thermischen Kopplung.

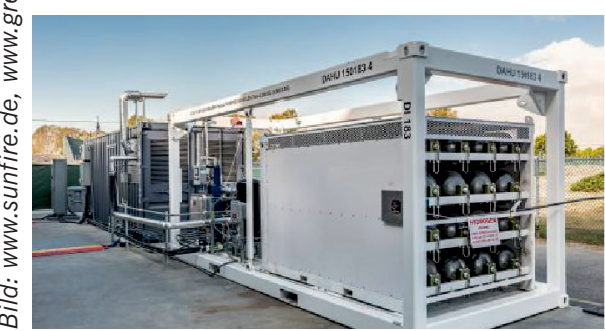

größte, kommerzielle RSOC-Anlage an Boing ausgeliefert [80]. Diese wurde am MicrogridTeststandort der US Navy in Kalifornien installiert und ermöglicht dort die hocheffiziente Langzeitspeicherung von elektrischer Überschussenergie aus erneuerbaren Energiequellen (Bild 12). Das vollintegrierte System kann in Phasen hoher Energieerzeugung in angeschlossenen Wind-

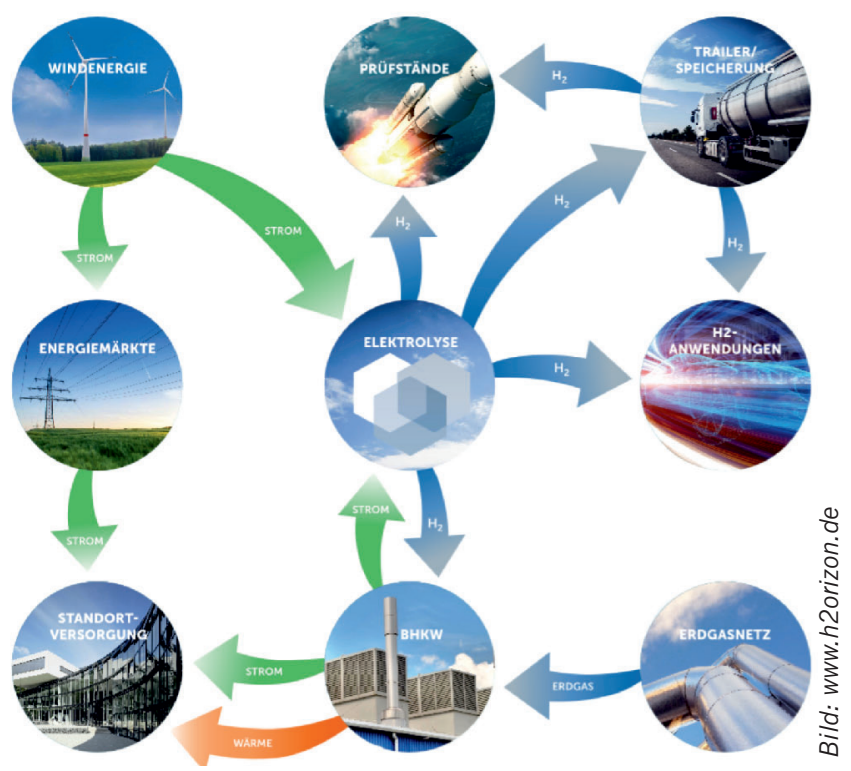
kraft- und Photovoltaik-

Bild 11 Synergetischer Ansatz der Wasserstoffnutzung im Projekt H2Orizon. anlagen im Elektrolysebetrieb eine Nennleistung von $140 \mathrm{~kW}$ aufnehmen und so $42 \mathrm{~m}^{3}$ Wasserstoff pro Stunde mit einem Wirkungsgrad von bis zu $85 \%$ erzeugen. Dieser wird dann in hochkomprimierter Form mit einer Speicherkapazität von bis zu 600 kWh gespeichert. Im Vergleich zur Energiespeicherung in Batterien kann Wasserstoff ohne auftretende Selbstentladung auch über lange Zeiträume gespeichert werden, und die Investitionskosten für Wasserstoffspeicher sind deutlich geringer, da diese in ihrer Größe unabhängig von der RSOC-Einheit aufgebaut und erweitert werden können. Sinken dann die bereitgestellten Energiemengen in den Wind- und Photovoltaikanlagen, kann der Wasserstoff mit einer Brennstoffzellenleistung von $50 \mathrm{~kW}$ und einer Effizienz von bis $\mathrm{zu} 60 \%$ wieder in elektrische Energie umgewandelt werden. Die Umschaltung zwischen den beiden Betriebsarten kann innerhalb nur weniger Minuten erfolgen und erlaubt eine hohe Flexibilität der Anlagen. Der erzeugte Wasserstoff ist hochrein und kann in längeren Überschussenergiephasen auch außerhalb des Speichers in der Industrie und dem Transportsektor zum Einsatz kommen. Besteht über einen längeren Zeitraum ein zusätzlicher Energiebedarf, der nicht über den zuvor gespeicherten Wasserstoff gedeckt werden kann, können in der Brennstoffzelle zusätzlich Erd- und Biogas verstromt werden.

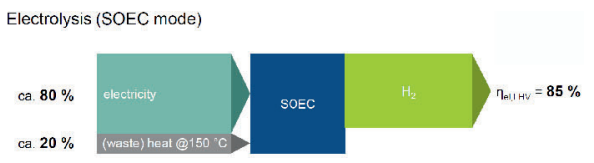

Fuel Cell (SOFC mode)

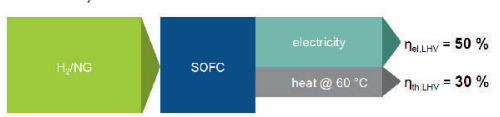

Da der Gesamtwirkungsgrad von RSOCAnlagen durch die thermische Kopplung mit ungenutzter Abwärme deutlich gesteigert werden kann, startete im März 2016 das im europäischen Horizon-2020-Programm geförderte Projekt GrInHy (Green Industrial Hydrogen). Bis Januar 2019 entwickeln die Partner Salzgitter Group, Boeing, Sunfire, VTT, Eifer, IPM und die Politechnico di Torino die Möglichkeit, das hohe Potenzial industrieller Abwärme für die Erzeugung von Wasserstoff und die Energiezwischenspeicherung über RSOC-Anlagen zugänglich zu machen [81]. Demonstriert wird dieses Potenzial durch die Integration der RSOC-Technik in die Stahlproduktionsanlage der Salzgitter Flachstahl GmbH. Ein Teil der Abwärme dieses Stahlwerkes soll für die Wasserdampferzeugung mit nachgekoppelter Elektrolyse mit einer Nennleistung von $150 \mathrm{~kW}$ genutzt werden (Bild 12). Der entstehende Wasserstoff wird zum einen für die RSOC-Anwendung gespeichert und zum anderen im Stahlwerk zur Erzeugung einer Schutzgas-Atmosphäre genutzt, um die Stahloxidation im Glühprozess zu vermeiden. Im Brennstoffzellenbetrieb wird die Abwärme der RSOC-Anlage in der Stahlfabrik und die erzeugte elektrische Energie zur Netzstabilisierung genutzt. Die Demonstrationsanlage wird dabei so ausgelegt, dass sie auf mehrere Megawatt skalierbar ist und in verschiedenen, energieintensiven Industriefeldern, wie beispielsweise der Siliziumproduktion in der Solarindustrie und der Ammoniaksynthese in der chemischen Industrie, eingesetzt werden kann.

\section{Literatur}

Die Literaturstellen zu dieser Jahresübersicht sind auf der BWK-Homepage über den Menüpunkt "Literaturverzeichnisse" aufrufbar.

www.eBWK.de 